\title{
Polypharmacy is an Indicator of Bad Practice and Low Quality in General Medicine
}

\section{Turabian JL*}

Department of Family and Community Medicine, Health Center Santa Maria de Benquerencia, Spain

*Corresponding author: Jose Luis Turabian, Specialist in Family and Community

\section{Mini Review}

Volume 2 Issue 4

Received Date: July 08, 2019

Published Date: July 19, 2019

DOI: $10.23880 /$ jqhe- 16000130

Medicine, Health Center Santa Maria de Benquerencia, Toledo, Spain, Email: jturabianf@hotmail.com

\section{Abstract}

Quality indicators are increasingly used as a tool to achieve safe and quality clinical care. A significant number of them focus on drug therapy, but few address the problem of polypharmacy in general medicine. All patients, especially elderly patients, those with certain pathologies, those with multimorbidity, or those who live in institutions, are exposed to polypharmacy. The prescription of contraindicated or potentially inappropriate medications is also common. Although polypharmacy is sometimes unavoidable, this indicator has been associated with increased morbidity and mortality. The prevalence of polypharmacy is high, and could reach $20 \%$. But, the main thing is that there is a great variability among general practitioners (GPs), which can vary from 4-5\% until 18-30\% according to GP, in the same geographical area and with lists of random and similar patients. Thus, the main cause of polypharmacy (of excessive use of drugs) is the professional; the prevalence of polypharmacy does not justify itself exclusively by the presence of the multimorbidity or of elderly people, neither is randomly distributed. Polypharmacy does not depend on the size GP' patients list (large lists may have little polypharmacy and small lists a lot of polypharmacy). It can be hypothesized that the presence of polypharmacy is an indicator of malpractice and poor quality of the general medical service, which should be used to improve the clinical care of patients. Therefore, it is imperative to monitor and optimize the use of medications in general medicine. This creates an opportunity to minimize adverse outcomes related to the use of medications and to improve the quality of care, possible cost savings and improve clinical outcomes. Additional research should deepen this proposal that high frequency of polypharmacy between different practices in general medicine is an indicator of poor quality of care in those GPs.

Keywords: Polypharmacy; Sanitary Attention; Quality Of Care; Medication Problems; Multimorbidity; General Practice; Inappropriate Prescribing; Theoretical Study; Aged Care

\section{Introduction}

Pharmacological prescription is one of the main facets of the general practitioner / family doctor (GP). The medical prescription corresponds to a complex act, which requires knowledge, professional experience, specific skills, a great sense of responsibility and an ethical attitude. The prescription of medications by the health 


\section{Journal of Quality in Health Care \& Economics}

professional is the result of a series of considerations and decisions related to the evolution of a disease and the role played by drugs in their treatment. The GP, at the time of making the pharmacological prescription, must also share the expectations with his patient, provide him with the information he needs, verify that he knows the risks to which he is subjected when using a medication and make sure that, the prescribed treatment, is within of the patient's economic possibilities [1,2].

The prevalence of polypharmacy, and consequently the increase in health costs, both by the use of drugs and indirectly by the iatrogenic effects of pharmacological interactions, adverse drug reactions, and greater morbidity and hospitalizations $[3,4]$.

In addition, the professional requirement to perform an "evidence based medicine" clashes with the tendency of over diagnosis, excessive treatment, multimorbidity and, consequently, polypharmacy $[5,6]$.

Multimorbidity is generally defined as the coexistence of two or more long-term conditions within an individual with the superposition of mental, cardiovascular, diabetes, cancer and respiratory diseases- It is a generalized phenomenon that affects the health of populations throughout the world, with the greatest burden among people or disadvantaged subpopulations, and has become a serious public health problem due to its negative consequences on the quality of life, the greater tendency to disability and mortality, polypharmacy and the cost of use of health services. Multimorbidity produces a considerable increase of medical services, which mainly falls on GPs [4].

In addition, the multimorbidity is greater in elderly patients. Worldwide, the population is aging. In almost all countries, the proportion of the population over 65 is growing faster than in any other age group. Between 2015 and 2030, it is expected that the number of people aged 65 or over worldwide will increase from 900 to 1,400 million. This increase in elderly people will significantly increase the demand for care services for the elderly, multimorbidity and polypharmacy [7].

The concept of the use of multiple medicines (polypharmacy) or of "poly medicated patient" varies depending on the source consulted, but the basic definition is quite simple: the prescription of more medications than are clinically appropriate $[3,8]$.

In general, polypharmacy has been defined in quantitative terms, although there seems to be no consensus on where to establish the limit from which we would be talking about polypharmacy, and in any case they are almost always arbitrary criteria. For some authors, taking only two medications would be polypharmacy, and for others it would be the daily consumption of four, five or even eight drugs. The most widespread number seems to be that of 5 drugs used chronically, a figure from which, there is a relationship with the inappropriate use of medicines. It should be noted that the frequency of adverse drugs reactions (ADR) is $6 \%$ when a patient takes two medications, $50 \%$ when he takes five and almost $100 \%$ when he takes eight or more medications $[9,10]$. It can therefore be said emphatically that problems related to medication, and especially to polypharmacy, are common in adults (especially among elderly patients) and it can cause harm $[11,12]$.

Low-quality pharmacological care reports are not uncommon. Adverse health outcomes related to medications for the population, and especially the elderly, include falls, strokes, delirium and death, as well as a wide variety of adverse drug reactions and drug-drug interactions [13].

On the other hand, only a limited number of studies have been published explicitly using indicators of quality use of medicines, including the construction of indicators for monitoring the quality of prescriptions in general practice [14].

In this way, various data of quality use of medicines have been reported, or indicators for measuring quality of medicines in clinical areas (geriatrics and obstetrics) or in specific diseases, such as diarrhea and pneumonia, quality indicators for assessing antimicrobial prescribing, prescriptions for proton pump inhibitors written by GPs, or quality indicators for antibiotic treatment of respiratory tract infections in general practice, among others [15-18].

The combination of the expansion of elderly populations and concerns about variability in the quality of care has driven the development of sets of indicators of quality of care with the aim of monitoring and improving the use of medicines throughout weather. Indicators are the gold standard for evaluating the quality of many aspects of health care. More specifically, quality indicators of medication-related care are summary measures that should be used as a guide to monitor, evaluate, and improve the use of medication that affects the quality of care and patient outcomes. However, it is common that quality indicators of medical care do not always focus on 


\section{Journal of Quality in Health Care \& Economics}

the use of medications. This lack of recognition of medicines in the current sets of health care quality indicators may reflect an uncertainty (especially in the sector of care for the elderly, which is the segment with the highest prevalence of polypharmacy) with respect to the best way to evaluate use of drugs [7].

Finally, it must be taking into account that the issue of polypharmacy, and within this, the attention of the quality and meaning of polypharmacy, is a crucial and complex issue. It is crucial because its increase, in relation to the multimorbidity, the over-diagnosis, the medicalization and the increase in costs, shows a rapid growth. It is a complex issue because of the very nature of these variables and because of the inherent difficulties in the criteria and the measurement of quality [19].

All health care systems require valid ways to evaluate the provision of services, and they need to be vigilant to check new ideas and hypotheses about the quality of service. In this scenario, the objective of this article, based on the experience of the author, and a narrative review of the topic, is to favouring a reflection on the identification of quality indicators for the responsible use of medicines in primary health care. And mainly, to present the hypothesis that the presence of polypharmacy is an indicator of malpractice and poor quality of the medical service of general medicine, which should be used to improve the clinical care of patients.

\section{Discussion}

Quality indicators are increasingly used as a tool to achieve safe and quality clinical care, achieve costeffective therapy, and help professional learning, remuneration, accreditation and financial incentives. A significant number of quality indicators focuses on drug therapy, but few address the problem of polypharmacy in general medicine, where the greatest number of drug prescriptions are produced, where most of older patients and patients with multimorbidity are treated, and where, the pharmacological treatments of different hospital specialists, serving different facets of the same patient converge, and in which these specialists usually introduce new drugs, use pharmacological associations, or employ high doses, sometimes without taking into account the set of health problems and potential risks of the patient. It is the GP who must coordinate and supervise this complex context. And although the possible indicators of quality in this level of attention are a hot topic, it lacks hypotheses, suggestions and proposals [20-22].
Polypharmacy, drug-related problems, inappropriate prescribing, and Medication-related quality of care Medications are probably the most important health care technology in preventing illness, disability, and death in the population. But, on the other hand, the problem of the use of medications is one of the most socially relevant in all countries [23].

Although polypharmacy is sometimes unavoidable, polypharmacy has been associated with increased morbidity and mortality [24]. Polypharmacy is an increasing problem, leading to increased morbidity and mortality, especially in older, multi morbid patients. Consequently, there is a need for reduction of polypharmacy. Se dice que la polifarmacia is un indicator de multimorbidity. Multimorbidity is usually defined as the coexistence of two or more long term conditions within an individual with the overlapping of mental, cardiovascular, diabetes, cancer and respiratory diseases, is a generalized phenomenon that affects the health of populations throughout the world, with the highest burden among individuals or subpopulations disadvantaged, having become a serious public health problem due to its negative consequences on the quality of life, the greater tendency to disability and mortality, polypharmacy, and cost of utilization of health services, and that give place to a considerable burden of care, which falls heavily on the primary health care provider [4].

But, multimorbidity is not simply a problem of chronological ageing, neither it is randomly distributed, and it come about most in deprived areas than in the affluent ones, and with a greater mix of social, mental and physical problems [25].

Drug-related problems are common in general medicine, and even more in aged care. Despite all the progress in medical care, including care for the elderly, it is still reported that drug-related problems occur frequently (and very often in elderly patients), are important factors for hospitalization and reduced quality of life in older adults. At this level of primary care, can be frequent inappropriate prescribing, for example of really cleared medications in elderly patients; Thus, has been communicated that virtually $100 \%$ of older patients have at least one drugs-related problem as a factor to be highlighted, the chronic renal failure has a prevalence of $50 \%$ in these patients, and the prescription for renal elimination drugs can be identified in more than $15 \%$ of them [26-29]. 


\section{Journal of Quality in Health Care \& Economics}

All medications can potentially lead to medicationrelated problems. A greater number of medications received, and the identification of more than 2 medication-related problems in a patient, are signs of very high risk of medication misadventure [30].

It has been reported that about $60 \%$ of patients may be exposed to at least one potentially inappropriate medication (identified by the Beers criterion), $80 \%$ of patients may be exposed to drugs that contribute to the Drug Burden Index (DBI)> 0, and $90 \%$ of patients may be exposed to polypharmacy (i.e. $\geq 5$ medications). Exposure to potentially harmful medications, as identified by DBI> 0 and by polypharmacy (i.e. $\geq 5$ medications) is associated with lower self-rated quality of life [31].

The potential harms of some medications can outweigh their potential benefits (inappropriate use of medications). Despite recommendations to avoid the use of potentially inappropriate medications in older adults, the prevalence of the use of potentially inappropriate medications is high in different settings, including residential care for the elderly. In addition, of course, the use of potentially inappropriate medications (especially for older adults) represents a substantial cost that can be reduced [32].

Thus, it has been described, especially in elderly people, the excessive use of high-risk medications associated with falls (70\%), medications with moderate to strong anticholinergic properties (50\%), benzodiazepines (40\%) and antipsychotics $(30 \%)[7,33]$.

In addition to the elders in the community, patients with dementia, and especially those who live in residential care centers for the elderly, have a particularly high risk of harm with medications. In these patients, polypharmacy has been identified in $90 \%$ of them (with a very high average of 10 drugs per person); one third of these patients were prescribed an antipsychotic medication; and it was found that $50 \%$ were taking at least one potentially inappropriate medication. The combination of antipsychotics and antidepressants was the pharmacological interaction observed more frequently, and it was prescribed in $16 \%$ of patients [34].

Besides the inappropriate use of benzodiazepines and psychotropic in general, this inappropriate use of drugs, has been reported in proton pump inhibitors, analgesics (including opiates), laxatives, NSAIDs and antacids, etc [35].

Drug-drug interactions, adverse drug reactions and polypharmacy Drug-drug interaction (DDI) is the modification that the action of a drug undergoes due to the simultaneous presence of another in the organism. This modification is usually translated into a variation of the intensity (increase or decrease) of the usual effect or the appearance of a different effect (sub therapeutic, therapeutic or toxicological) as expected. The prevalence of DDIs in outpatient population may be high because of polypharmacy. One common consequence of polypharmacy is the high rate of inverse drug reactions (ADRs), mainly from DDIs. So, DDIs are a significant cause for ADRs. The risk of a DDI in any particular patient increases with the number of co-existing diseases and the number of drugs prescribed [10,35-37].

ADRs cause a lot of suffering to the patient with considerable mortality and morbidity, as well as an increase in medical care expenses. Its importance becomes bigger and bigger in relation to the current increase in the use of drugs, polypharmacy and multimorbidity $[38,39]$.

An ADR is any response to a drug that is harmful and unintentional, and that takes place at doses that are normally applied in humans for the prophylaxis, diagnosis or treatment of diseases, or for the restoration, correction or modification of physiological functions. This term also includes all the harmful clinical consequences derived from the dependence, abuse and misuse of medications, including those caused by use outside the authorized conditions and those caused by medication errors. So, ADRs and drug allergies- as a subset of ADRs- make a significant public health concern, complicating 5 to $15 \%$ of therapeutic drug courses. So, it can be admitted that ADRs occur in approximately $20 \%$ of the patients. They may result in diminished quality of life, increased physician visits, health care costs, hospitalizations, and even death $[40,41]$.

Both patient age and polypharmacy use are risk factors for ADR-related. So, the incidence of ADRs has particularly increased among patients 65 years and older with as many as 1 in 20 persons. However, although it is recognized that the incidence of adverse drug reactions increases with age, this increase is mainly due to altered pharmacodynamics and pharmacokinetics, as well as multiple prescription and the effect of the disease instead of the effect of age itself $[42,43]$.

Polypharmacy is an indicator of low quality in general medicine. The prevalence of polypharmacy es alta, $y$ podría is between $10 \%$ and $20 \%$. Pero, lo principal es que there is a great variability among GPs, que puede variar from $4-5 \%$ until $18-30 \%$ according to GP. So, the main 


\section{Journal of Quality in Health Care \& Economics}

cause of polypharmacy (of excessive use of drugs) is the professional; the prevalencia de la polypharmacy does not se justifica exclusively por la presencia the multimorbidity o de personas mayores. Polypharmacy does not depend on the size of the GP patients list (large lists may have little polypharmacy and small lists may have a lot of polypharmacy).

Thus, in a first approach to the topic, it can be thought that the polypharmacy in the general practice practice is connected with other variables and circumstances (from multimorbidity, to the presence of a greater number of elderly people, approach biomedical vs. bio psychosocial approach, lack of personnel, excessive demand, etc.). Consideration of these factors may make us think that polypharmacy does not necessarily mean that it is inadequate; the quality of the system for the provision of general medical services as a whole should be evaluated.

The above being true, however, the fact of the wide variation in polypharmacy rates that can be observed between general practice consultations that share geographical bases, and that their patient lists do not have biases regarding the prevalence of elderly patients, of multimorbidity, size of patient lists or number of auxiliary personnel, strongly suggests that the presence of polypharmacy is an indicator of poor medical quality.

In this situation, should the problem be addressed by means of inspections or advice to the professionals? Regardless of what "inspection" means in practice, it requires the existence of certain standards acceptable to professionals, administrators and politicians, which makes this option complex. Quality audit, on the other hand, is a more ambiguous concept, but one that tends to be defined by professionals [19].

Approaches can be described for the correction of polypharmacy in general medicine. In any case, several approaches can be described for the correction of polypharmacy in general medicine Table 1.

\begin{tabular}{|c|c|}
\hline Main Approaches & Concepts \\
\hline 1. Deprescription & $\begin{array}{l}\text { De-prescription is a symmetrical process and closely linked to the prescription } \\
\text { that requires prudence, deliberation and assimilation of the ethical principles } \\
\text { that direct the medical duty }\end{array}$ \\
\hline \multirow{4}{*}{$\begin{array}{l}\text { 2. Factors associated with the use of } \\
\text { potential harmful medications and } \\
\text { polypharmacy }\end{array}$} & $\begin{array}{l}\text { A) The experience of the health system (the conflict between the implicit trust } \\
\text { in the health system and its negative experience in de-prescription) }\end{array}$ \\
\hline & B) The practical aspects of the use of medications \\
\hline & C) The management of medication problems \\
\hline & $\begin{array}{l}\text { D) The problems in doctor-patient communication (such as passive listening } \\
\text { and paternalistic consultations), and the beliefs of the doctor and the patient. }\end{array}$ \\
\hline $\begin{array}{l}\text { 3. Techniques to judiciously avoid } \\
\text { polypharmacy }\end{array}$ & $\begin{array}{l}\text { Use drugs only in authorized indications; avoid starting treatment with two } \\
\text { drugs from the same drug group; avoid to using a drug longer than indicated } \\
\text { (for example, do not use benzodiazepines chronically); and not treating ADR } \\
\text { with other drugs }\end{array}$ \\
\hline \multirow{6}{*}{$\begin{array}{l}\text { 4-Interventions to address the } \\
\text { prevalence of polypharmacy and the } \\
\text { adequacy of the use of medications }\end{array}$} & A) The implementation of a drug reconciliation service \\
\hline & B) Conduct audits and feedback to staff and health professionals \\
\hline & C) Develop scripts to help the discussion between doctors and patients \\
\hline & D) Review specific prescription guidelines for seniors with multimorbidity \\
\hline & E) Implement electronic medication records to address medication adequacy \\
\hline & $\begin{array}{l}\text { F) Interdisciplinary collaboration between the different levels of care and } \\
\text { administration, as well as coordination with pharmaceutical professionals }\end{array}$ \\
\hline
\end{tabular}

Table 1: Approaches Can Be Described For The Correction Of Polypharmacy In General Medicine.

1. Deprescription: Polypharmacy is, in part, the other side of the coin of multimorbidity when it is focused, as is usually done, with the "evidence-based" guidelines of each isolated disease. And, in addition, polypharmacy in turn causes more morbidity, basically iatrogenic. It must be borne in mind that the possible pharmacological interactions multiply exponentially as the number of drugs present in a patient increases, and such interactions, in each particular case, are not even described in the literature, being a new phenomenon not yet explored [10,25,37,44-46].

2. It has been identified patient involvement in de prescribing and coordination of care as key issues for de prescribing among older multi morbid patients with 


\section{Journal of Quality in Health Care \& Economics}

polypharmacy. GPs concerns regarding patients' devaluation should not prevent them from actively discussing the reduction of drugs [47-49].

3. Some main factors associated with the use of potential harmful medications and polypharmacy have been identified, as the experience of the health system, the management of medication problems; and the problems in doctor-patient communication [11,50,51].

4. Techniques to judiciously avoid polypharmacy. In this way, some techniques could be suggested to judiciously avoid polypharmacy: use drugs only in authorized indications; avoid starting treatment with two drugs from the same drug group, etc $[7,52]$.

5. 4-Interventions to address the prevalence of polypharmacy and the adequacy of the use of medications, as the implementation of a drug reconciliation service, conduct audits and feedback to staff and health professionals, etc [24].

\section{Conclusion}

Quality indicators are increasingly used as a tool to achieve safe and quality clinical care, achieve costeffective therapy, and help professional learning, remuneration, accreditation and financial incentives. A significant number of quality indicators focus on drug therapy, but few address the problem of polytherapy in general medicine.

The patients treated in general medicine, and especially the elderly, those with certain pathologies such as dementia, those with multimorbidity, or those who live in institutions, are commonly exposed to polypharmacy. The prescription of contraindicated medications, high risk medication as antipsychotics, psychotropic medication in general, benzodiazepines, medications with a high anticholinergic load and potentially inappropriate drug combinations is also common. Therefore, there may be a substantial margin for improving prescription, and especially for older people who are clinically fragile and exposed to multiple medications.

Although polypharmacy is sometimes unavoidable, it has been associated with increased morbidity and mortality. The prevalence of polypharmacy es alta, y podría is between $10 \%$ and $20 \%$. Pero, lo principal es que there is a great variability among GPs, que puede variar from $4-5 \%$ until $18-30 \%$ according to GP in the same geographical area and with similar patients. The main cause of polypharmacy (of excessive use of drugs) is the professional; the prevalencia de la polypharmacy does not se justifica exclusively por la presencia the multimorbidity o de personas mayores, neither it is randomly distributed. Polypharmacy does not depend on the size GP' patients list (large lists may have little polypharmacy and small lists a lot of polypharmacy).

Consequently, the presence of polypharmacy is an indicator of malpractice and poor quality of the general medical service, which should be used to improve the clinical care of patients. Therefore, it is imperative to monitor and optimize the use of drugs in general medicine. There is an urgent need for interventions and development of new models of care to address the safety of medicines. This creates an opportunity to minimize adverse outcomes related to the use of medications and to improve the quality of care, possible cost savings and improve clinical outcomes. The adoption of a prudent and reflective model of care should be encouraged. Interdisciplinary collaboration between the different levels of care and administration, as well as coordination with pharmaceutical professionals, is among the factors affecting medication safety. Additional research should clarify whether this proposal of using the frequency of polypharmacy between different practices in general medicine is a useful indicator of poor quality of care.

\section{References}

1. Stonington SD, Holmes SM, Hansen H, Greene JA, Wailoo KA, et al. (2018) Case Studies in Social Medicine Attending to Structural Forces in Clinical Practice. N Engl J Med 379: 1958-1961.

2. Turabian JL (2019) Psychosocial aspects of drug prescription: recognizing these phenomena to improve the quality of clinical practice. Archives of Pharmacology and Therapeutics.

3. Masnoon N, Shakib S, Kalisch Ellett L, Caughey GE (2017) What is polypharmacy? A systematic review of definitions. BMC Geriatr 17(1): 230.

4. Turabián JL, Pérez Franco B (2016) A way of helping "Mr. Minotaur" and "Ms. Ariadne" to exit from the multiple morbidity labyrinth: The "master problems". Semergen 42(1): 38-48.

5. Turabian JL (2018) Why do Patients Not Meet The Pharamalogical Treatment? Arch Pharmacol Ther 1(1): 1-8.

6. Turabian JL (2018) Doctor-Patient Relationship in Pharmacological Treatment: Discontinuation and Adherence. COJ Rev \& Res 1(5): 1-8.

7. Hillen JB, Vitry A, Caughey GE (2018) Medicationrelated quality of care in residential aged care: an 


\section{Journal of Quality in Health Care \& Economics}

Australian experience. Int J Qual Health Care 31(4): 298-306.

8. Monégat M, Sermet C, Perronnin M, Rococo E (2014) Polypharmacy: Definitions, Measurement and Stakes Involved Review of the Literature and Measurement Tests. Questions d'économie de la santé 204.

9. Rodríguez del Río E, Martínez Agüero M, Arias Fernández L, Martín-Sánchez FJ (2016) Global intervention in the polymedicated patient. Gac Sanit 30(5): 402.

10. Turabian JL, Perez Franco B (2015) Helping "Dr. Theseus" leave the labyrinth of multiple drug interactions. BMJ 350: h1059.

11. Parekh N, Gahagan B, Ward L, Ali K (2019) 'They must help if the doctor gives them to you': a qualitative study of the older person's lived experience of medication-related problems. Age Ageing 48 (1): 14751.

12. Turabian JL (2019) Relevant Characteristics for Elderly Patient Biopsicosocial Care in General Medicine. Archives of Community and Family Medicine 2(1): 48-55.

13. Marengoni A, Onder G (2015) Guidelines, polypharmacy, and drug-drug interactions in patients with multimorbidity. BMJ 350: h1059.

14. Rasmussen H, Sondergaard J, Andersen M (2009) Prescription quality indicators. Ugeskr Laeger 171(10): 797-799.

15. Nguyen HT, Wirtz VJ, Haaijer Ruskamp FM, Taxis K (2012) Indicators of quality use of medicines in South-East Asian countries: a systematic review. Trop Med Int Health 17(12): 1552-1566.

16. Pont LG, Morgan TK, Williamson M, Haaijer FM, van Driel ML (2017) Validity of prescribing indicators for assessing quality of antibiotic use in Australian general practice. Int J Pharm Pract 25(1): 66-74.

17. Levy Neumand O, Carniaux F, Bonaz B, Durand A, Roblin X (2007) Proton pump inhibitors in general medicine. Comparison of routine practices with marketing authorization indications. Gastroenterol Clin Biol 31(1): 78-83.

18. Hansen MP, Bjerrum L, Gahrn Hansen B, Christensen RD, Davidsen JR, et al. (2013) Quality indicators for treatment of respiratory tract infections? An assessment by Danish general practitioners. Eur J Gen Pract 19(2): 85-91.

19. Klein R, Hall P (1975) Caring for quality in the caring services. London: Centre for Studies in Social Policy.

20. Turabian JL (1995) Family and community medicine notebooks: an introduction to the principles of family medicine.

21. Campbell SM, Godman B, Diogene E, Fürst J, Gustafsson LL, et al. (2015) Quality indicators as a tool in improving the introduction of new medicines. Basic Clin Pharmacol Toxicol 116(2): 146-157.

22. Fujita K1, Moles RJ, Chen TF (2018) Quality indicators for responsible use of medicines: a systematic review. BMJ Open 8(7): e020437.

23. Turabian JL (2019) The role of general practitioner in the study of adverse drug reactions epidemiology in ambulatory care setting. Arch Community Med Public Health 5(1): 003-007.

24. Jokanovic N, Wang KN, Dooley MJ, Lalic S, Tan EC, et al. (2017) Prioritizing interventions to manage polypharmacy in Australian aged care facilities. Res Social Adm Pharm 13(3): 564-574.

25. Turabian JL (2018) Notes for a Theory of Multimorbidity in General Medicine: The Problem of Multimorbidity Care is Not in Practice, but in the Lack of Theoretical Conceptualization. Journal of Public Health and General Medicine 1(1): 1-7.

26. Roughead EE, Semple SJ, Gilbert AL (2003) Quality use of medicines in aged-care facilities in Australia. Drugs Aging 20(9): 643-653.

27. Gheewala PA, Peterson GM, Curtain CM, Nishtala PS, Hannan PJ, et al. (2014) Impact of the pharmacist medication review services on drug-related problems and potentially inappropriate prescribing of renally cleared medications in residents of aged care facilities. Drugs Aging 31(11): 825-835.

28. Kosari S, McDerby N, Thomas J, Naunton M (2018) Quality use of medicines in aged care facilities: A need for new models of care. J Clin Pharm Ther 43(4): 591593.

29. Stafford AC, Tenni PC, Peterson GM, Jackson SL, Hejlesen A, et al. (2009) Drug-related problems identified in medication reviews by Australian pharmacists. Pharm World Sci 31(2): 216-223. 


\section{Journal of Quality in Health Care \& Economics}

30. Kaur S, Roberts JA, Roberts MS (2012) Evaluation of medication-related problems in medication reviews: a comparative perspective. Ann Pharmacother 46(78): 972-982.

31. Bosboom PR, Alfonso H, Almeida OP, Beer C (2012) Use of Potentially Harmful Medications and HealthRelated Quality of Life among People with Dementia Living in Residential Aged Care Facilities. Dement Geriatr Cogn Dis Extra 2(1): 361-371.

32. Harrison SL, Kouladjian, O'Donnell L, Milte R, Dyer SM, et al. (2018) Costs of potentially inappropriate medication use in residential aged care facilities. BMC Geriatr 18(1): 9.

33. Westbury J, Beld K, Jackson S, Peterson G (2010) Review of psychotropic medication in Tasmanian residential aged care facilities. Australas J Ageing 29(2): 72-76.

34. Somers M, Rose E, Simmonds D, Whitelaw C, Calver J, et al. (2010) Quality use of medicines in residential aged care. Aust Fam Physician 39(6): 413-436.

35. Tulner LR, Frankfort SV, Gijsen GJ, van Campen JP, Koks CH, Beijnen JH (2008) Drug-drug interactions in a geriatric outpatient cohort: prevalence and relevance. Drugs Aging 25(4): 343-455.

36. Tulner LR, Kuper IM, Frankfort SV, van Campen JP, Koks CH, et al. (2009) Discrepancies in reported drug use in geriatric outpatients: relevance to adverse events and drug-drug interactions. Am J Geriatr Pharmacother 7(2): 93-104.

37. Patton K, Borshoff DC (2018) Adverse drug reactions. Anaesthesia 73(S1): 76-84.

38. Coleman JJ, Pontefract SK (2016) Adverse drug reactions. Clin Med (Lond) 16(5): 481-485.

39. Pourpak Z, Fazlollahi MR, Fattahi F (2008) Understanding adverse drug reactions and drug allergies: principles, diagnosis and treatment aspects. Recent Pat Inflamm Allergy Drug Discov 2 (1): 24-46.

40. Gholami K, Ziaie S, Shalviri G (2008) Adverse drug reactions induced by cardiovascular drugs in outpatients. Pharm Pract (Granada) 6(1): 51-55.

41. Bourgeois FT, Shannon MW, Valim C, Mandl KD (2010) Adverse drug events in the outpatient setting: An 11-year national analysis. Pharmacoepidemiol Drug Saf 19(9): 901-910.
42. Denham MJ (1990) Adverse drug reactions. Br Med Bull 46(1): 53-62.

43. Muth $\mathrm{C}$, van den Akker M, Blom JW, Mallen CD, Rochon J, et al. (2014) The Ariadne principles: how to handle multimorbidity in primary care consultations. BMC Medicine 12: 223.

44. Orueta R, Sánchez Oropesa A, Gómez Calcerrada RM, Arriola M, Nieto I (2015) Therapeutic appropriateness in chronic patients. Rev Clin Med Fam 8(1).

45. Frank C (2014) Deprescribing: a new word to guide medication review. CMAJ 186: 407-408.

46. Fernández Liz E (2013) How to review the medication in patients with multiple chronic conditions?. Aten Primaria 45(5): 233-234.

47. Schuling J, Gebben H, Veehof L, Haaijer-Ruskamp F (2012) Deprescribing medication in very elderly patients with multimorbidity: the view of Dutch GPs. A qualitative study. BMC Family Practice 13: 56.

48. Woodward MC (2003) Deprescribing: Achieving Better Health Outcomes for Older. People Through Reducing Medications. J Pharm Pract Res 33(4): 323328.

49. Turabian JL (2019) Doctor-patient relationship in the de-prescription of pharmacological treatment. Fam Med Care 2.

50. Turabian JL (2019) Doctor-Patient Relationship and Multimorbidity: The More Extraordinary a Case Seems, the Easier it is to Solve it. Arch Fam Med Gen Pract 4(1): 82-89.

51. Turabián JL, Perez Franco B (2014) Reflections on the present and future of family medicine. Gac Sanit 28(3): 259.

52. Zechmann S, Trueb C, Valeri F, Streit S, Senn O, et al. (2019) Barriers and enablers for deprescribing among older, multimorbid patients with polypharmacy: an explorative study from Switzerland. BMC Fam Pract 20(1): 64. 